\section{LOCAL SCIENTIFIC SOCIETIES}

I.

WE have devoted part of our space this week to a kind of Census of our Local Scientific Societies. It will be seen that in these Islands we already muster a goodly number, but no friend of Science would consider the number satisfactory; it does not, we are sure-seeing that there are twenty counties in England and Wales, and a much larger proportion in Scotland and Ireland, which appear not to boast of any such society-rcpresent the truc activity of the different regions from which, so to speak, the societies are fed. We do not suppose that our list is accurate; indeed our present purpose in printing it is to gather information. We hope that many socicties exist which are not in our list ; we fear that some have already ceased to exist since the time that Sir Walter Elliot, with infinite pains, compiled some of the data on which we have had to rely in the absence of information forwarded by the officers of the societies themselves.

On the whole, however, all lovers of Science and advocates for the spread of scientific education among all classes, ought to feel greatly gratified at the rapid increase during recent years, of local scientific societies and fieldclubs indicated by the dates of foundation to be found in our list. No more unmistakeable sign of a general elevation of taste, of the spread of the scientific influence and of a desire for scientific knowledge, can, we think, be obtained, than this starting-up, in all parts of the country, of societies for the express purpose of scientific work in one form or another, and that generally as a means of recreation. By far the greater number of the societies have had their birth within recent years. IVith one or two exceptions, the older societies are not very promincnly scientific, while as a rule the recently founded ones bear on their very front the declaration that they have been establiched solely for the pursuit of Science.

This is indeed very encouraging, more especially when we reflect that this result is no cutcome of any temporary burst of enthusiasm, of any exciting scientific "revival" agitation, but is simply the natural fruit of the slow but sure development of the scientific spirit in our country.

From the information which las been kindly sent us by the secretaries of the various societies many interesting facts might be presented, and many curious and valuable inferences drawn. It will be seen from the list, that the societies are very unequally distributed over the country, quite a busy hive of them being clustered around the border counties of England and Scotland, while not a few counties in both countries, as well as in Ireland, are quite unrepresented, and many large counties by but a single society. Why should this be? Is it to be attributed to the backward state of intelligence and education in the unrepresented districts? We do not think so; we believe that in every county in the three kingdoms, men and women will be found with an intelligent love of Science, a desire for scientific knowledge, and a wish for the spread of scientific education. Such people only require to be roused to perceive the advantages of the establishment of scientific societies and field-clubs in their midst; if only some one would take the initiative and start such societics where they do not at present exist, we have no fear, if judicious means be used, that ample success will follow. From the large number of members belonging to many of the societies members belonging to all classes of society, it will be seen that it is now considered honourable to be connected with such an association; and although in most socicties there is only a small nucleus of working members, still while efforts should be made to engage all in the work, the non-working majority should be considered as, at least by their subscriptions and good-will, they help on the good cause.

Into these and other details we hope to cnter in one or more future articles, founded partly on the statistics we possess. $\Lambda$ the present time, when a Committee of the British Association is considering the whole question of our local Societies, we think it useful to point out the extreme importance of an increascd activity in this direction. The recent action of the Government in aiding the establish ment of Science Schools has enormously increased the advantages which such local associations may confer on outsiders, while at the same time it has greatly widened the recruiting ground. And it is in this double capacity that the formation, encouragement, and extension of such societies should be the care of all, whether scientific in their tastes or not; while, to fricnds of Science it is crucial, for Government aid, under existing arrangcments, can only come where there are Science Classes; and without Government aid, in nine cases out of ten, the thing will fall to the ground altogether, or drag on an existence of second-rate utility.

If there then be any Scientific Societies without Science Classes attached to them, let them be assured that their museums are comparatively valueless; and further, that their museum must always remain as it is, for though it is clear to many that the Government must soon supply typical collections to museums which are available for teaching purposes, it is equally clear that there is no reason why they should do so to museums the utility of which is limited merely to members of a society.

Again: If there be any Scientific Societies without Science Classes attached to them let them be assured that their courses of lectures will prove of the least possible value; for mere lectures to those anxious to learn, but who are debarred from more serious study, are more than disappointing, they are hurtful.

In the ordinary course of things the Lecture should be the precursor of the Science Class. The Science Class should drive the student to the Museum, and from the zcalous students the society should be recruited.

There is one point in which all will acknowledge our local socicties have of late made considerable progress, and here again the British Association has been helpful to them-we refer to the more general establishment of courses of lectures, and the more general engagement of competent men of science, to place things new and strange before their members. Let not such lecturers forget that their duty is almost a sacred one; though he may not be a Davy, there may yet be a Faraday among the audience, one who may be gained or lost to Scicnce according as the lecturer does his allotted work well or ill.

This brings us to another point. Why should not physical and chemical apparatus available for highclass experimental lectures be occasionally seen in our museums or in rooms adjoining them? Why should the stuffed crocodile and curious weapon of some 
southern race of savages have it all their own way to the extent that they do? Here, no doubt, our Government has been greatly at fault, for after all, humble local museums, parvis componere magna, are little British Museums, and there is no help provided by the government for any physical, or chemical, or astronomical students in the British Museum. But though our government is behind the age in London, the South Kensington authorities are alive to the weak point in the armour, as regards the provinces, and if a local society will only establish a Science Class, travelling collections of the most important modern scientific instruments are to be had for the asking; and we may hope that ere long there may be a model museum at South Kensington, doing for physical science what is done for it in Paris by the magnificent Conservatoire des Arts et Métiers, a museum in which the applications of Science, and the implements for the teaching of Science hold the first place.

\section{FARADAY ON SCIENTIFIC LECTURING}

$A \mathrm{~T}$ a time when the lecture season is commencing, we $A$ believe we shall be doing good service by.placing before those of our readers who are not already acquainted with them in Dr. Bence Jones" "Life of Faraday," the opinions of that great man on many points connected with lectures on Science.

They were written to a friend when Faraday was but 2 I years of age, but we believe he would have changed little though he might have added much if he had revised them in his later years. He commences by explaining that:-

"The subject upon which I shall dwell more particularly at present has been in my head for some considerable time, and it now bursts forth in all its confusion. The opportunities that I have latterly had of attending and obtaining instructions from various lecturers in their performance of the duty attached to that office, has enabled me to observe the various habits, peculiarities, excellencies, and defects of each of them as they were evident to me during the delivery. I did not wholly let this part of the things occurrent escape my notice, but when I found myself pleased, endeavoured to ascertain the particular circumstance that had affected me; also, whilst attending Mr. Brand and Mr. Powell in their lectures, I observed how the audience were affected, and by what their pleasure and their censure were drawn forth.

"On going to a lecture I generally get there before it begins; indeed, I consider it as an impropriety of no small magnitude to disturb the attention of an audience by entering amongst them in the midst of a lecture, and, indeed, bordering on an insult to the lecturer. By arriving there before the commencement, I have avoided this error, and have had time to observe the lecture-room."

$\mathrm{He}$ dwells on the form of the lecture-room, and then indicates how important a matter ventilation is.

"There is another circumstance to be considered with respect to a lecture-room of as much importance almost as light itself, and that is ventilation. How often have I felt oppression in the highest degree when surrounded by a number of other persons, and confined in one portion of air! How have I wished the lecture finished, the lights extinguished, and myself away merely to obtain a fresh supply of that element! The want of it caused the want of attention, of pleasure, and even of comfort, and not to bc regained without its previous admission. Attention to this is more particularly necessary in a lectureroom intended for night delivery, as the lights burning add considerably to the oppression produced on the body."

He then goes on :-

"Having thus thrown off, in a cursory manner, such thoughts as spontaneously entered my mind on this part of the subject, it appears proper next to consider the subject fit for the purposes of a lecture. Science is undeniably the most eminent in its fitness for this purpose. There is no part of it that may not be treated of, illustrated, and explained with profit and pleasure to the hearers in this manner. The facility, too, with which it allows of manual and experimental illustration, places it foremost in this class of subjects. After it come (as I conceive) arts and manufactures, the polite arts, belles lettres, and a list which may be extended until it includes almost every thought and idea in the mind of man, politics excepted. I was going to add religion to the exception, but remembered that it is explained and laid forth in the most popular and eminent manner in this way. The fitness of subjects, however, is connected in an inseparable manner with the kind of audience that is to be present, since excellent lectures in themselves would appear absurd if delivered before an audience that did not understand them. Anatomy would not do for the generality of audiences at the R. I. (Royal Institution), neither would metaphysics engage the attention of a company of schoolboys. Let the subject fit the audience, or otherwise success may be despaired of."

Now for the lecturer :-

"A lecturer may consider his audience as being polite or vulgar (terms I wish you to understand according to Shuffleton's new dictionary), learned or unlearned (with respect to the subject), listeners or gazers. Polite company expect to be entertained not only by the subject of the lecture, but by the manner of the lecturer; they look for respect, for language consonant to their dignity, and ideas on a level with their own. The vulgar-that is to say in general, those who will take the trouble of thinking, and the bees of business-wish for something that they can comprehend. This may be deep and elaborate for the learned, but for those who are as yet tyros and unacquainted with the subject must be simple and plain. Lastly, listeners expect reason and sense, whilst gazers only require a succession of words.

"These considerations should all of them engage the attention of the lecturer whilst preparing for his occupation, each particular having an influence on his arrangements proportionate to the nature of the company he expects. He should consider them connectedly, so as to keep engaged completely during the whole of the lecture the attention of his audience.

"I need not point out to the active mind of my friend the astonishing disproportion, or rather difference, in the perceptive powers of the eye and the ear, and the facility and clearness with which the first of these organs conveys ideas to the mind-ideas which, being thus gained, are held far more retentively and firmly in the memory than when introduced by the ear. Tis true the ear here labours under a disadvantage, which is that the lecturer may not always be qualified to state a fact with the utmost precision and clcarness that language allows him and that the ear cannot understand, and thus the complete action of the organ, or rather of its assigned portion of the sensorium, is not called forth; but this evidently points out to us the necessity of aiding it by using the eye also as a medium for the attainment of knowledge, and strikingly shows the necessity of apparatus.

"Apparatus, therefore, is an essential part of every lecture in which it can be introduced; but to apparatus should be added, at every convenient opportunity, illustrations that may not perhaps deserve the name of apparatus and of experiments, and yet may be introduced with considerable force and effect in proper places. Diagrams, and tables too, are necessary, or at least add in an 